\title{
Biomaterials-Mediated Regulation of Macrophage Cell Fate
}

\author{
Yining Liu ${ }^{1}$ and Tatiana Segura ${ }^{1,2,3 *}$ \\ ${ }^{1}$ Department of Biomedical Engineering, Duke University, Durham, NC, United States, ${ }^{2}$ Department of Neurology, Duke \\ University, Durham, NC, United States, ${ }^{3}$ Department of Dermatology, Duke University, Durham, NC, United States
}

Endogenous regeneration aims to rebuild and reinstate tissue function through enlisting natural self-repairing processes. Promoting endogenous regeneration by reducing tissue-damaging inflammatory responses while reinforcing self-resolving inflammatory processes is gaining popularity. In this approach, the immune system is recruited as the principal player to deposit a pro-reparative matrix and secrete pro-regenerative cytokines and growth factors. The natural wound healing cascade involves many immune system players (neutrophils, macrophages, T cells, B cells, etc.) that are likely to play important and indispensable roles in endogenous regeneration. These cells support both the innate and adaptive arms of the immune system and collectively orchestrate host responses to tissue damage. As the early responders during the innate immune

OPEN ACCESS

Edited by:

Qiang Wei,

Sichuan University, China

Reviewed by:

Lang Ma,

Sichuan University, China

Kunyu Zhang,

Johns Hopkins University,

United States

*Correspondence:

Tatiana Segura

tatiana.segura@duke.edu

Specialty section:

This article was submitted to Biomaterials,

a section of the journal Frontiers in Bioengineering and

Biotechnology

Received: 23 September 2020 Accepted: 23 November 2020 Published: 11 December 2020

Citation:

Liu Y and Segura T (2020) Biomaterials-Mediated Regulation of Macrophage Cell Fate. Front. Bioeng. Biotechnol. 8:609297. doi: $10.3389 /$ fbioe.2020.609297 response, macrophages have been studied for decades in the context of inflammatory and foreign body responses and were often considered a cell type to be avoided. The view on macrophages has evolved and it is now understood that macrophages should be directly engaged, and their phenotype modulated, to guide the timely transition of the immune response and reparative environment. One way to achieve this is to design immunomodulating biomaterials that can be placed where endogenous regeneration is desired and actively direct macrophage polarization. Upon encountering these biomaterials, macrophages are trained to perform more pro-regenerative roles and generate the appropriate environment for later stages of regeneration since they bridge the innate immune response and the adaptive immune response. This new design paradigm necessitates the understanding of how material design elicits differential macrophage phenotype activation. This review is focused on the macrophage-material interaction and how to engineer biomaterials to steer macrophage phenotypes for better tissue regeneration.

\footnotetext{
Keywords: macrophage, biomaterial, immunomodulation, regeneration, wound healing, phenotype, macrophage polarization, mechanotransduction
}

\section{INTRODUCTION}

Our knowledge of macrophages has a long-standing history (Figure 1). When macrophages were first discovered by Élie Metchnikoff, a Russian zoologist, in 1882, they were described as phagocytes that could accumulate at the point of inflammation and clear out invading pathogens (Metchnikoff, 1883). Metchnikoff identified a close connection between the mononuclear phagocytic cells in the spleen, lymph nodes, bone marrow and connective tissue, and he grouped them under the 
A

All phagocytic cells were classified together as the reticuloendothelial system. Aschoff, 1924

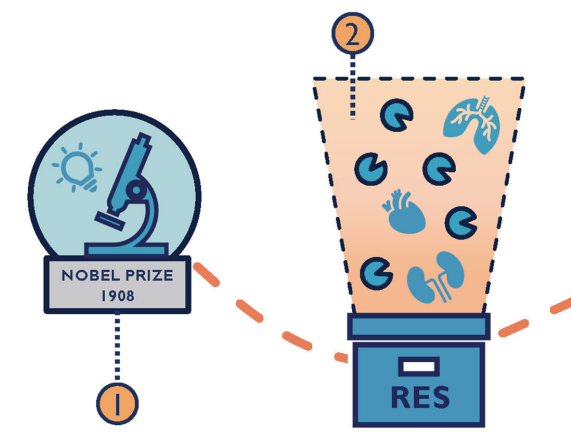

Macrophages were discovered as phagocytes. Metchnikoff, 1882
The mononuclear phagocyte system included bone marrow progenitors, blood monocytes and macrophages. Langevoort et al., 1970, van Furth et al., 1972
Macrophage heterogeneity was defined. Lichanska and Hume, 2000, Gordon and Taylor, 2005, Chorro et al., 2009, Wynn et al., 2013, Epelman et al., 2014

B
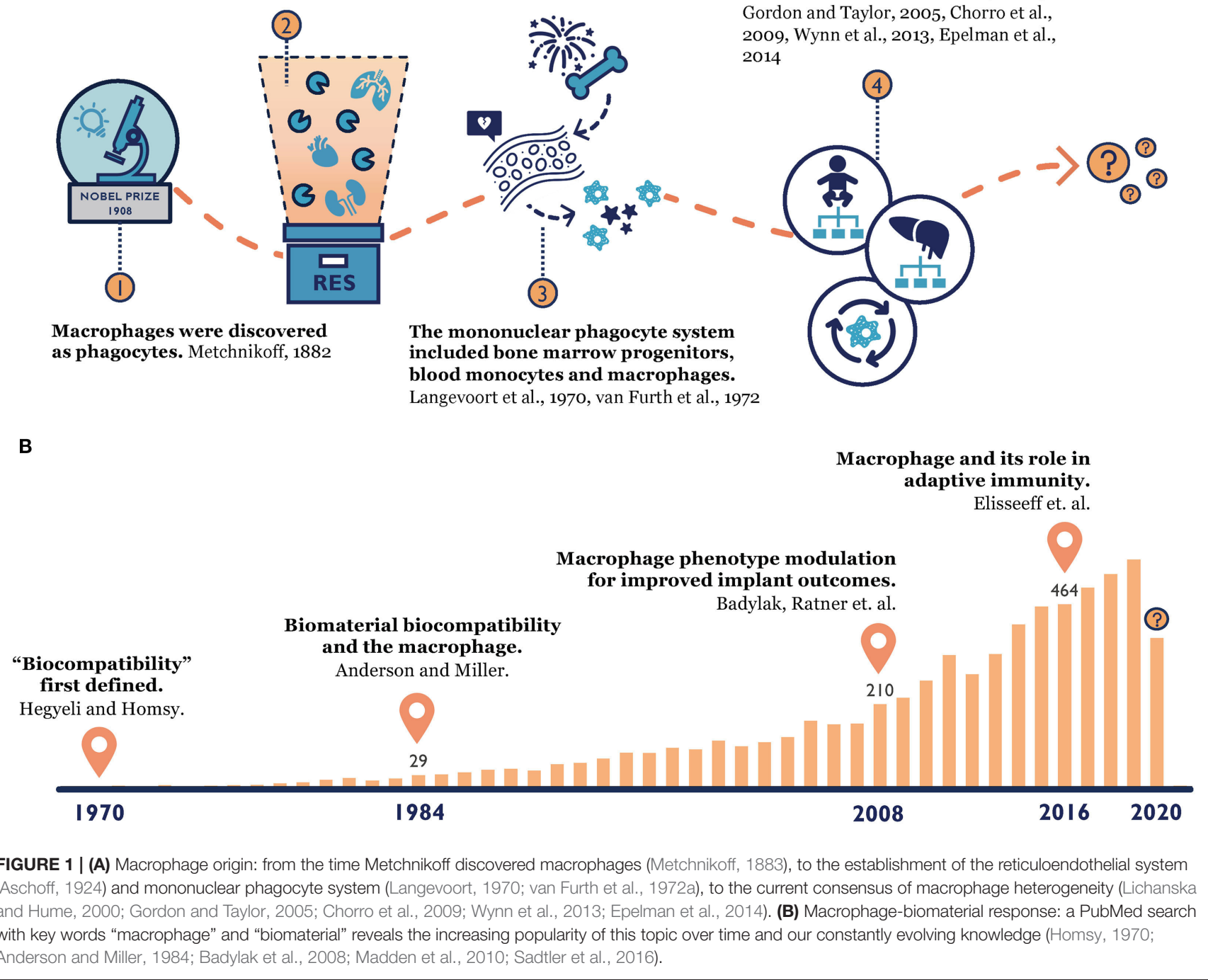

term "macrophage system" (van Furth et al., 1972b). This observation and the later founded phagocytosis theory laid a foundation for innate immunity (Metchnikoff, 1907; Tauber, 2003; Gordon, 2008; Underhill et al., 2016), which earned Metchnikoff a Nobel Prize in 1908. Since then, our understanding of macrophage origin, classification and function continues to evolve. In 1924, Acshoff developed the concept of the reticuloendothelial system (RES) to describe macrophages and other phagocytic cells (Aschoff, 1924). This concept was criticized for only considering cell function rather than their origins, and it was later replaced by the ontogeny-based term "mononuclear phagocyte system (MPS)" in 1969 (Langevoort, 1970; van Furth et al., 1972b; Van Furth, 1980). This widely accepted MPS model proposed that tissue macrophages were terminally differentiated from bone marrow progenitors and blood monocytes (Langevoort, 1970; van Furth et al., 1972b; Van Furth, 1980). However, toward the end of the 20th century, mounting evidence suggested that certain tissue macrophages could proliferate locally (Sawyer et al., 1982; Czernielewski and Demarchez, 1987; Ajami et al., 2007; Chorro et al., 2009). Instead of originating only from bone marrow, researchers found that most tissue macrophages' existence can be traced back to the embryonic stage (Chorro et al., 2009; Epelman et al., 2014). Therefore, macrophage heterogeneity was established and explored further over the last two decades, and hypotheses of macrophages' divergent origins started to prevail (Lichanska and Hume, 2000; Gordon and Taylor, 2005; Wynn et al., 2013). Still, many questions about macrophages have yet to be answered, such as the contribution of recruited monocyte-derived macrophages in the replenishment of tissue-resident macrophages and the functional differences between these two populations during an inflammatory response (Gordon and Taylor, 2005).

Macrophages play a pivotal role in tissue regeneration during injuries and diseases (Wynn et al., 2013). They coordinate with 
the rest of the immune system to create a pro-regenerative niche at the diseased site, and they recruit progenitor cells to support and promote healing (Martin and Leibovich, 2005; Eming et al., 2014). For instance, during the early stage of acute wound healing, macrophages work side by side with the other innate immune cells (e.g., neutrophils) to debride the wound and construct a provisional matrix (Eming et al., 2014). Together, these effector cells produce chemokines and growth factors to mobilize mesenchymal stem cells, fibroblasts as well as keratinocytes to restore the tissue (Mantovani et al., 2004). However, this endogenous regenerative ability diminishes with age and can also be disrupted in pathological conditions (Wells and Watt, 2018). In the case of diabetes, patients develop non-healing wounds because of the dysregulation in macrophage function, which leads to a perpetuating inflammatory environment and prevents reparative cell infiltration (Eming et al., 2014). These wounds have malfunctioning local milieus that deviate from those of healthy individuals' in both biochemical components (e.g., accumulation of inflammatory cytokines) and mechanical properties (e.g., degraded extracellular matrix) (Schultz and Wysocki, 2009; Christman, 2019). To repair damaged tissue by salvaging the body's natural healing ability, one emerging approach uses immunomodulatory biomaterials to promote immune-mediated tissue regeneration (Rice et al., 2013; Yu et al., 2016b). These materials are designed to actively engage the immune system and manipulate the infiltrating cells, especially macrophages, to perform regenerative functions. This immunomodulatory method thereby reconstructs a local pro-reparative niche and lays down a foundation for endogenous regeneration.

In recent years, more and more research points to macrophages' parts in bridging innate immunity with adaptive immunity and how this bridging role can be leveraged by immunomodulating biomaterials for promoting endogenous repair (Sadtler et al., 2016; Wolf et al., 2019). To this end, a comprehensive understanding of macrophage-biomaterial response is essential. Many excellent reviews cover macrophage mechanotransduction (McWhorter et al., 2015; Mennens et al., 2017; Adams et al., 2019; Jain et al., 2019; Meli et al., 2019; Gruber and Leifer, 2020) and its biomedical applications (Brown et al., 2014; Springer and Fischbach, 2016; Andorko and Jewell, 2017; Spiller and Koh, 2017; Li J. et al., 2018) from various angles. However, no existing review articles provide a current view of macrophage-material interaction from a practical bioengineering perspective. In this review, we synthesize the up-to-date understanding of macrophage biology and macrophage-material response. We also present a pragmatic guidebook for researchers to design biomaterials that can guide context-dependent macrophage polarization for optimal endogenous tissue regeneration.

\section{MACROPHAGE HETEROGENEITY AND PLASTICITY}

Macrophages are highly heterogeneous immune cells with great diversity in lineages, anatomical distribution, and functional subsets (Wynn et al., 2013). The idea that maintenance of tissue-resident macrophages in mice relies on the recruitment and differentiation of blood monocytes was once mainstream (van Furth et al., 1972b; Wynn et al., 2013; Ginhoux and Jung, 2014). However, recent fate-mapping studies challenged this idea by comprehensively demonstrating that most tissueresident macrophages are derived from yolk sacs and fetal livers in the embryonic stage, and they can self-renew to persist into adulthood independent of monocytes (Ginhoux et al., 2010; Schulz et al., 2012; Hashimoto et al., 2013; Wynn et al., 2013; Yona et al., 2013). Only some highly specialized macrophage populations, such as those in the skin, intestine, and splenic marginal zone, require continuous repopulation by bonemarrow-derived precursors (Schulz et al., 2012; Tamoutounour et al., 2013; Yona et al., 2013; Bain et al., 2014). This dual origin theory of tissue macrophages also holds true in humans (Bajpai et al., 2018).

Macrophage plasticity is another hallmark that supports multifaceted roles for macrophages in different tissues, organs and disease states (Mosser and Edwards, 2008). Besides the control of intrinsic differentiation pathways, macrophages are also subject to the influence of the local microenvironment and perform context-based functions (Gosselin et al., 2014; Lavin et al., 2014; Wills et al., 2017). For example, when peritoneal macrophages were engrafted into donor lungs, these macrophages upregulated lung macrophage-specific genes, demonstrating that differentiated tissue-resident macrophages retain their plasticity and that local tissue cues can alter macrophage function (Lavin et al., 2014). However, while macrophage plasticity can dictate its function, it is also possible to have functionally and developmentally distinct macrophage populations coexisting in the same tissue, such as large and small peritoneal macrophages (Ghosn et al., 2010). Therefore, when designing biomaterials to engage macrophages, it is essential to characterize macrophages with a comprehensive paradigm that takes into account their origin, plasticity, and overall heterogeneity within tissues.

Macrophage phenotype is difficult to define because of inherent heterogeneity in this cell population and their plasticity in response to environmental changes (Figure 2). When researchers first tried to understand macrophage phenotype, a modular approach mirroring $\mathrm{T}$ helper type 1 and T helper type 2 polarization was used to divide macrophage phenotypes into M1 and M2 (classical activation and alternative activation) (Nathan et al., 1983; Stein et al., 1992; Mills et al., 2000; Mills, 2012, 2015). This paradigm was useful for early in vitro study as it clearly defined the activation cytokines and expected functional changes (e.g., surface receptors, ligands, produced cytokines) for each phenotype. As more evidence accumulated, a few disparate macrophage phenotypes emerged that could not simply be grouped into "M2" (Edwards et al., 2006). Therefore, the M1/M2 dichotomy was further expanded to include subcategories like M2a, M2b, and M2c (Mantovani et al., 2004; Martinez et al., 2008; Biswas and Mantovani, 2010). This categorical view still ran the risk of oversimplifying the intricate population of macrophages by force-fitting them into defined categories. Over the past decade, scientists conducting epigenetics, gene expression, and 


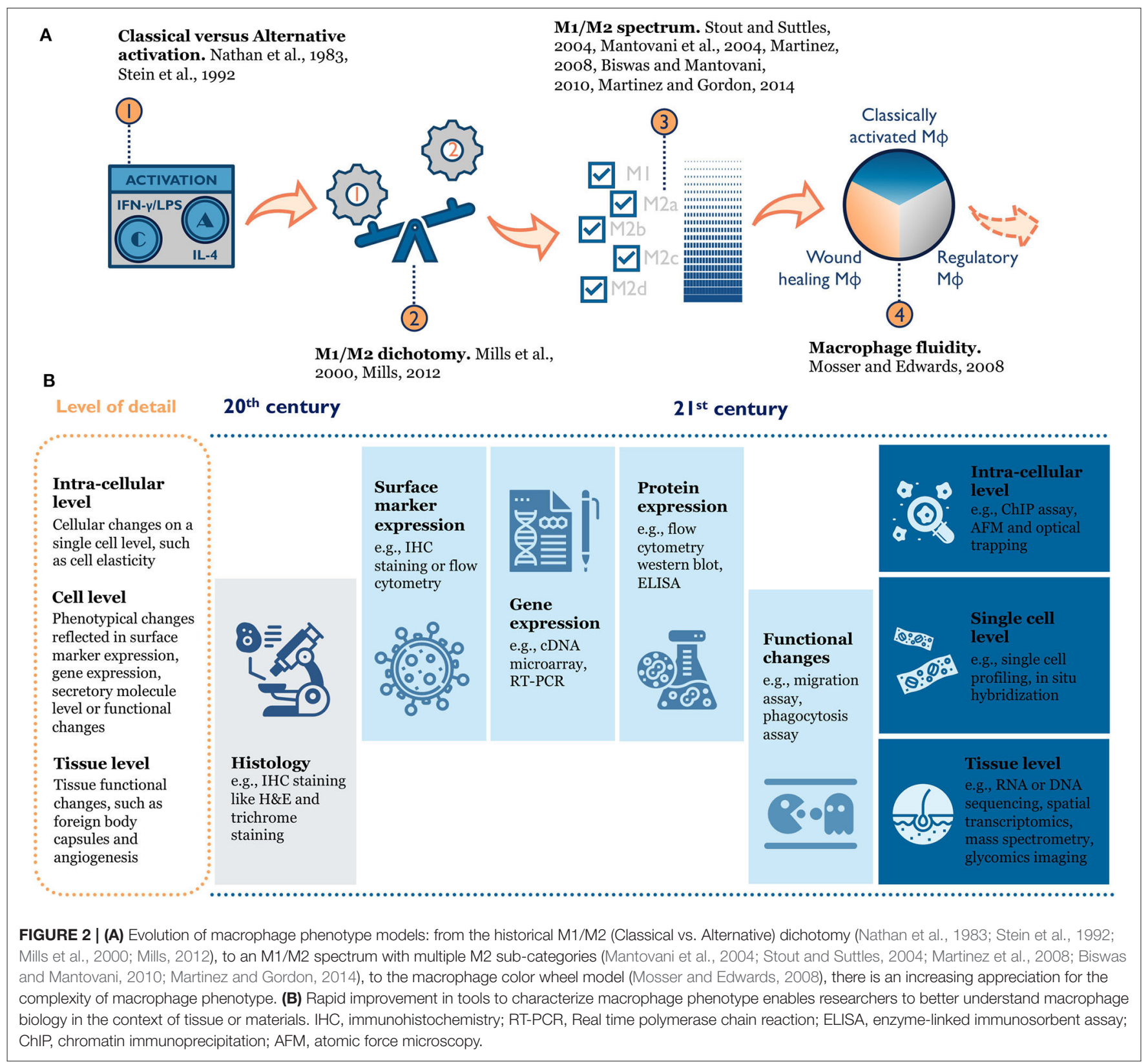

functional studies discovered new macrophage phenotypes that the traditional M1/M2 model failed to characterize (e.g., tumorassociated macrophages) (Mosser and Edwards, 2008; Xue et al., 2014; Malyshev and Malyshev, 2015). Thus, a color wheel model with different "shades" of activation was proposed to account for both fundamental functions and the context-specific roles macrophages perform (Mosser and Edwards, 2008; Ginhoux et al., 2016). In other words, macrophage phenotype should be seen as a dynamic and not a static process (Mosser and Edwards, 2008; Wills et al., 2017).

Given the fluidity of macrophage phenotype and the plasticity of the cells, it's very hard to both accurately define them and comprehensively characterize them. As with many biological assays, common tools used to study macrophage phenotype only capture a snapshot at the moment of sampling. In reality, macrophages are constantly adapting to the changing environment and their phenotypes should not be viewed as an end-point definition (Mosser and Edwards, 2008). A universal language on how to define macrophages has yet to be widely accepted and adopted (Murray et al., 2014), especially in in vivo settings because of the many factors at play. For example, macrophages in wounds exhibit a complicated phenotype with features found in both M1 and M2 macrophages (Daley et al., 2010; Novak and Koh, 2013). Thus, the term "macrophage phenotype" and the phenotype definitions should be considered with careful deliberation. When researchers refer to phenotype 
results from different studies or report their findings, a multiaspect description needs to be provided to capture the full picture of activated macrophages, such as the origin of the cells, the systemic and local milieu, the combination of markers and functions they share, and the timing of activation.

\section{A DOUBLE EDGE SWORD IN VIVO}

Macrophages are central to many disease stages and serve multifaceted roles during physiological and pathological processes (Gordon, 1995). Because of their plasticity, macrophages are highly susceptive to environmental stimuli and they act as a double edge sword in vivo (Wynn et al., 2013). In a normal, healthy adult, macrophages play integral roles in maintaining tissue homeostasis, inflammation and repair. On one hand, they are the diligent "janitors," clearing out dead cells and extraneous cellular debris as part of the regular metabolic process (Mosser and Edwards, 2008). Distinct tissue-resident macrophages perform tissue-specific homeostatic functions, such as the clearance of apoptotic neutrophils and erythrocytes in the spleen and liver. If a timely removal of these cells by macrophages fails, severe results ensue, such as neutropenia, splenomegaly, and reduced body weight (Gordy et al., 2011). On the other hand, macrophages act as the primary sensor of danger signals and the first responders in the innate immune system for host defense (Gordon, 1995). In the case of acute wound healing, macrophages govern the inflammation stage and orchestrate regeneration (Leibovich and Ross, 1975). Within minutes of injury, tissue-resident macrophages recognize danger signals, like damage-associated molecular patterns, and help initiate the local inflammatory response (Minutti et al., 2016). Monocyte-derived macrophages are then recruited to the wound by the local presence of inflammatory chemokines and cytokines, such as monocyte chemoattractant protein-1 (MCP1 ), tumor necrosis factor-alpha (TNF- $\alpha$ ), and interferon-gamma (IFN- $\gamma$ ), and they further amplify the inflammatory response (Krzyszczyk et al., 2018). These new-comers actively attempt to phagocytose foreign materials and produce proteases (e.g., matrix metalloproteinases/MMPs) to break down the damaged matrix (Ginhoux and Jung, 2014). They also secrete various factors (e.g., chemokines, cytokines) to coordinate support cells and assist tissue reconstruction. Selective depletion of macrophages in mice during the inflammatory phase impairs wound vascularization and contraction (Mirza et al., 2009; Lucas et al., 2010). Conversely, removing macrophages during the tissue formation phase leads to severe hemorrhage in wound tissues (Mirza et al., 2009; Lucas et al., 2010). Both cases further demonstrate that macrophages are central players in wound healing. When pathological conditions occur, macrophages' homeostatic and reparative functions can be overridden, which has led to a causal association of macrophages with many diseases.

Disturbances in macrophage function contribute to a broad spectrum of pathologies, such as cancer and inflammatory disorders (Wynn et al., 2013). For diabetes patients, the underlying pathologies, like elevated glucose, are believed to promote a pro-inflammatory macrophage phenotype (Wen et al., 2006; Mirza and Koh, 2011; Bannon et al., 2013). These cells accumulate in the wound bed and contribute to the uncontrolled production of pro-inflammatory cytokines, chemokines and proteases, as well as growth factors (Eming et al., 2010). An overabundance of MMPs, as an example, can break down critical extracellular matrix (ECM) proteins and prevent new tissue formation (Wysocki et al., 1993). Overall, the imbalance of these key molecules, like pro-inflammatory cytokines, forms a vicious cycle by maintaining a macrophage pro-inflammatory phenotype and preventing regenerative cell infiltration. A predominance of pro-inflammatory macrophages is considered a major hallmark for non-healing wounds, and restoring the properly-regulated transition in macrophage phenotypes remains key to the development of a potential solution (Willenborg and Eming, 2014).

Macrophage-directed therapies are promising for the treatment of a range of diseases (Springer and Fischbach, 2016; Spiller and Koh, 2017; Li R. et al., 2018). Generally, the treatments can be categorized into 4 types: (1) exogenous macrophage supplementation; (2) delivery of molecules to modulate endogenous macrophage phenotypes or alter their numbers; (3) delivery of biomaterials to modulate endogenous macrophage phenotypes; (4) a selective combination of 1-3. The second approach has been most studied. Researchers using this approach delivered key molecules (e.g., recombinant interleukin4/IL-4, TNF- $\alpha$ neutralizing antibody) to recruit endogenous macrophages and induce their pro-regenerative function or block pro-inflammatory signaling pathways or products (Salmon-Ehr et al., 2000; Goren et al., 2007). However, several disadvantages have arisen with these methods. Given that the details regarding timing and specific roles of each macrophage phenotype are still yet to be fully elucidated, an optimal dosage to elicit desired phenotypes in a timely manner is hard to achieve. Additionally, the delivery of molecules or cells directly to the wound bed also ignores the importance of the microenvironmental context in shaping macrophage responses (Gosselin et al., 2014; Lavin et al., 2014). In a pro-inflammatory milieu, excessive amounts of proteases might expedite the degradation of active molecules, and exogenous activated M2 macrophages could be skewed to perform M1 function. To achieve long-lasting healing outcomes, it is crucial to first address the aberrant microenvironment. A combined method, with immunomodulatory biomaterials to reconstruct the local environment, will be better suited to fine-tune macrophage response and achieve better regeneration.

\section{MACROPHAGE-MATERIAL RESPONSE: WHAT DO WE KNOW AND WHAT SHOULD WE DO?}

The design of biomaterial scaffolds that are capable of modulating the local microenvironment requires a closer look at the macrophage-material interaction and the resulting changes in macrophage phenotype. This interaction has been studied extensively in the context of foreign body response since the early 1970s (Coleman et al., 1974). A foreign body response 
(FBR) is characterized by the persisting existence of immune cells, particularly macrophages, and the encapsulation of the implanted material by fibrotic tissues (Anderson et al., 2008). Macrophages oversee the inflammation process of the host reaction to implants (Figure 3). They function to clear out debris and foreign materials via phagocytosis, produce enzymes to remodel the provisional matrix, and secrete signaling molecules to recruit support cells, such as fibroblasts. In an attempt to minimize the impact of a foreign implant on the body, macrophages fuse into foreign body giant cells (FBGC), and actively seek to degrade the implant. If this process fails, FBGCs work with fibroblasts to deposit collagen layers and wall off the implant by forming a dense fibrotic capsule around it (Anderson et al., 2008). FBR can render implanted biomaterials or medical devices non-functional by preventing drug release, reducing blood supply, and causing contraction and pain. Surprisingly, even now it is still unclear which macrophage phenotype plays a major role in initiating FBR. M1 macrophages are closely related to inflammation and reduced M1 presence has been observed to attenuate FBR (Goreish et al., 2004). In addition, multiple studies proved that a higher M2 to M1 ratio was associated with more constructive remodeling and implant vascularization (Badylak et al., 2008; Brown et al., 2012; Spiller et al., 2014). Conversely, immunoregulatory cytokines (e.g., platelet-derived growth factor/PDGF, transforming growth factor-beta/TGF- $\beta$ ), inflammatory cytokines (e.g., TNF- $\alpha$ ), and chemokines (e.g., MCP-1) are implicated in the formation of FBR, connecting both M1 and M2 macrophages to this process (Kao et al., 1995; Hernandez-Pando et al., 2000; Gretzer et al., 2006; Rodriguez et al., 2009). Taken together, these results suggest that either both M1 and M2 macrophages contribute to FBR collaboratively, or a hybrid M1-M2 phenotype exists throughout FBR. The latter hypothesis is further proof that the M1/M2 dichotomy falls short in accurately categorizing macrophage phenotypes.

Given the impact of FBR on implants, traditional strategies for biomaterial design focus on evading or suppressing inflammation, especially macrophage response, in order to mitigate FBR. For example, surface hydrophilicity can be used to overcome non-specific protein absorption and reduce FBGC formation (Quinn et al., 1997; Jenney and Anderson, 1999; Voskerician et al., 2003; Collier et al., 2004). However, growing evidence has shown that macrophage engagement during implantation can be harnessed to improve implant success rates (Spiller et al., 2014; Yu et al., 2016a) and that a timely transition from M1 to M2 phenotype benefits tissue remodeling (Badylak et al., 2008; Brown et al., 2012; Spiller et al., 2014; Yu et al., 2016a; Witherel et al., 2020). Many approaches to promote this M1-M2 shift, like a sequential delivery of immunomodulatory cytokines IFN- $\gamma$ and IL-4, have achieved some positive outcomes (Mokarram et al., 2012; Spiller et al., 2015). This evolving knowledge base of macrophage-material interaction has contributed to a new era of immune-modulating materials where material design is centered around desired immune responses.

During macrophage-material interaction in vivo, the material itself acts as a temporary niche for macrophages to reside in, and the properties of the material weigh in on macrophage phenotypes. As discussed in the previous section, macrophages are known to adapt to microenvironmental features, such as biochemical and physical signals. The molecular mechanisms behind common soluble factors, like IL-4 and lipopolysaccharides (LPS), have been extensively studied, while new information continues to emerge with the advance of biotechnologies (Martinez and Gordon, 2014; Ramirez et al., 2017). Remarkably, emerging evidence suggests that long-ignored physical cues play an important modulating role in macrophage activation, but the signaling pathways have yet to be fully elucidated (McWhorter et al., 2015; Jain et al., 2019) (Table 1, refer to Supplementary Table 1 for more detail information). A broad range of material properties, such as pore size (Madden et al., 2010; Garg et al., 2013; Sussman et al., 2014; Wang et al., 2014), shape and geometry (Matlaga et al., 1976; Veiseh et al., 2015), stiffness (Blakney et al., 2012; Sadtler et al., 2019), topography (Chen et al., 2010; Wang et al., 2016; Shayan et al., 2018) and surface modification (e.g., hydrophilicity, integrin engagement) (Brodbeck et al., 2002; Antonov et al., 2011; Blakney et al., 2012; Swartzlander et al., 2015; Cha et al., 2017), have been proven to modulate macrophage behavior and tune implantation outcomes. However, a lot of these studies simply observed correlations between material designs and macrophage phenotypes without exploring further the molecular mechanism behind them. For instance, poly (2-hydroxyethyl methacrylate-co-methacrylic acid) hydrogel scaffolds with pore diameters of $30-40 \mu \mathrm{m}$ showed maximum vascularization and minimal fibrotic response following implantation (Madden et al., 2010). This outcome was coupled with an increased number of macrophages in the implants expressing both nitric oxide synthase 2 (NOS2, M1 marker) and macrophage mannose receptor (MMR, M2 marker) at the same time (Madden et al., 2010). A similar study using the same scaffold system revealed that the pro-angiogenic $34 \mu \mathrm{m}$ porous implants had more macrophages accumulating in the pores with a primarily M1 marker expression (NOS2 and IL-1R1) (Sussman et al., 2014). Another work using expanded polytetrafluoroethylene scaffolds demonstrated that larger intranodal distance $(4.4 \mu \mathrm{m})$ induced a significantly thinner capsule in vivo but promoted early proinflammatory cytokine production and gene transcription by monocytes/macrophages in vitro (Bota et al., 2010). These studies highlight the potential of using scaffolds with tunable pore sizes to guide macrophage phenotypes, but the results did not consistently point to one particular optimal pore size inducing a preferable macrophage phenotype to achieve desired outcomes. This is partly due to the complex in vivo environment and varying experimental settings, such as the different materials and animal models used, and the limited biomarkers selected for macrophage characterization. Ultimately, material design needs to target a clear mechanotransduction pathway of macrophages so that it can be translatable between material systems and disease applications.

In the past two decades, well-defined in vitro systems have been employed to more specifically understand the mechanotransduction mechanisms that lead to phenotypic macrophage changes to common mechanical signals (Figure 4). For example, preventing bone marrow-derived macrophages 


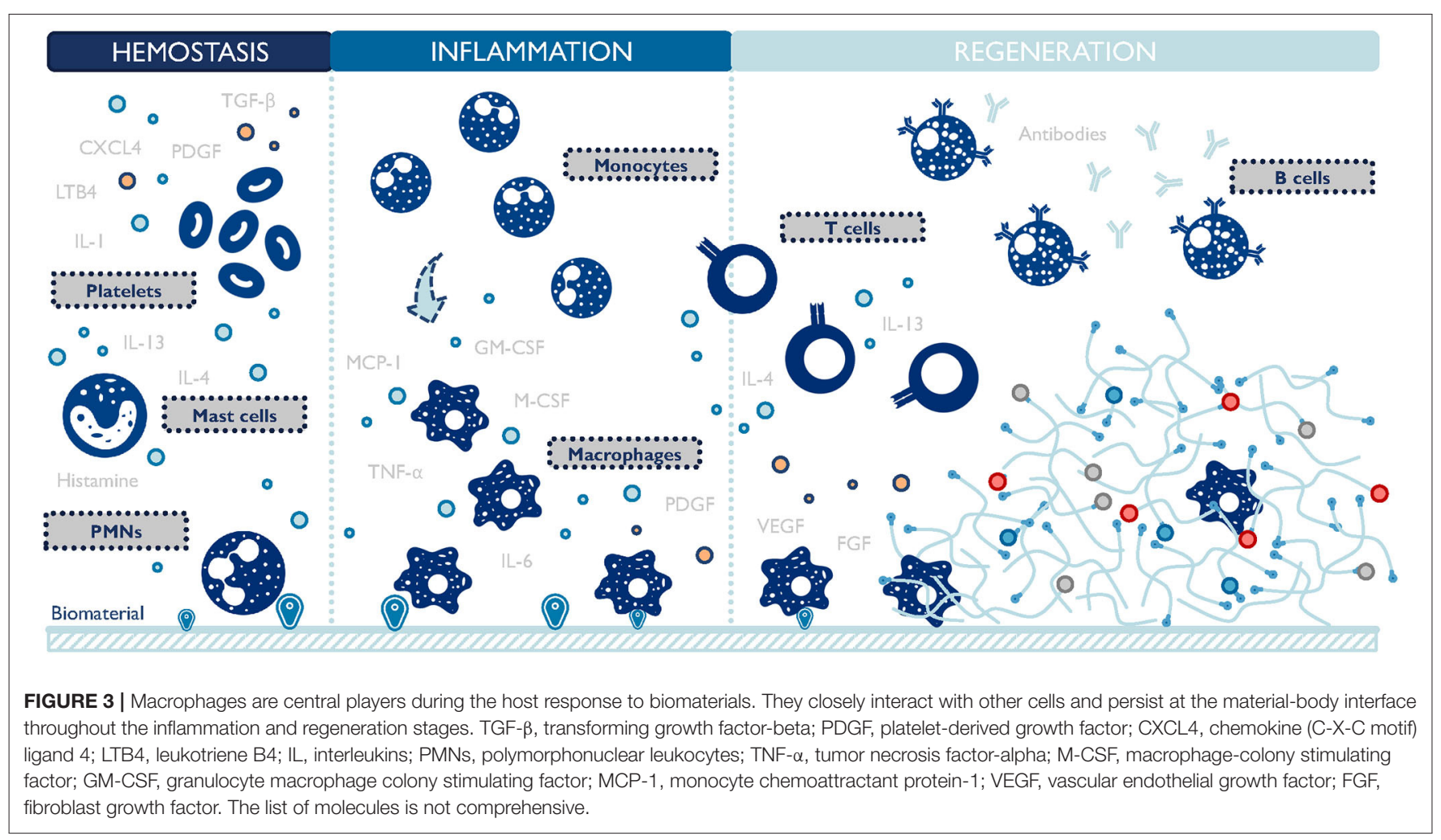

TABLE 1 | Modulating macrophage phenotype by physical cues.

\begin{tabular}{|c|c|}
\hline Physical cues & Rationale \\
\hline Stiffness & $\begin{array}{l}\text { Stiffness-dependent changes generally include enhanced adhesion and spreading, increased actin and cytoskeletal stiffness, } \\
\text { increase in proliferation and migration as well as increased phagocytosis. But the connection between stiffness and macrophage } \\
\text { phenotype remains complicated }\end{array}$ \\
\hline Surface topography & $\begin{array}{l}\text { Surface topography, such as roughness and micropatterns, can guide macrophage behavior by modifying their adhesion, spreading, } \\
\text { elongation, and motility on the surface. Specifically, using topography design to force macrophages into elongated cell shape is } \\
\text { shown to promote a pro-regenerative M2 phenotype }\end{array}$ \\
\hline Surface modification & $\begin{array}{l}\text { Surface modification like coating or modifying surface chemistry directly alters how macrophages engage with the material. There is a } \\
\text { clear role for integrin-mediated regulation of macrophage migration, phagocytosis, and activation, but the precise mechanisms still } \\
\text { remain relatively unknown }\end{array}$ \\
\hline Geometry & $\begin{array}{l}\text { Scaffold geometry affects macrophage phenotype by spatially confining macrophages and limiting their spreading, thereby leads to } \\
\text { an alteration in actin polymerization, chromatin compaction, and epigenetic alterations }\end{array}$ \\
\hline Hemodynamic loads & $\begin{array}{l}\text { Macrophages reside within mechanically active tissues and are constantly exposed to dynamic external forces, such as stretch and } \\
\text { cyclic strain. These forces can cause macrophages to elongate along the direction of force, therefore affecting their phenotypes. } \\
\text { However, there is still no consensus on the mechanism of mechanical forces in influencing macrophage function }\end{array}$ \\
\hline
\end{tabular}

or RAW264.7 cells from spreading by spatial confinement, such as using micropatterned surface, microporous substrates or cell crowding, reduced LPS-stimulated transcriptional programs and cytokine expression (Jain and Vogel, 2018). The study elegantly illustrated that confining macrophages in a small pore limited actin polymerization and thus lowered the nuclear translocation of the actin-dependent transcription co-factor, myocardin-related transcription factor-A, which downregulated the inflammatory response (e.g., less proinflammatory cytokine secretion, lower phagocytic potential of macrophages). Spatial constraints also led to the chromatin compaction and epigenetic alterations (e.g., lower histone deacetylase 3 levels, increased H3K36-dimethylation). Although the results of these studies shed light on some potential pathways that guide macrophage response to mechanical stimuli, macrophages cultured on a two-dimensional surface still cannot fully recapitulate macrophages' structures and function in 3D culture or in vivo (Van Goethem et al., 2011). Therefore, future studies on mechanotransduction mechanisms of macrophages should turn to $3 \mathrm{D}$ systems with a range of independently controlled properties in order to achieve a far-reaching physiological significance. 


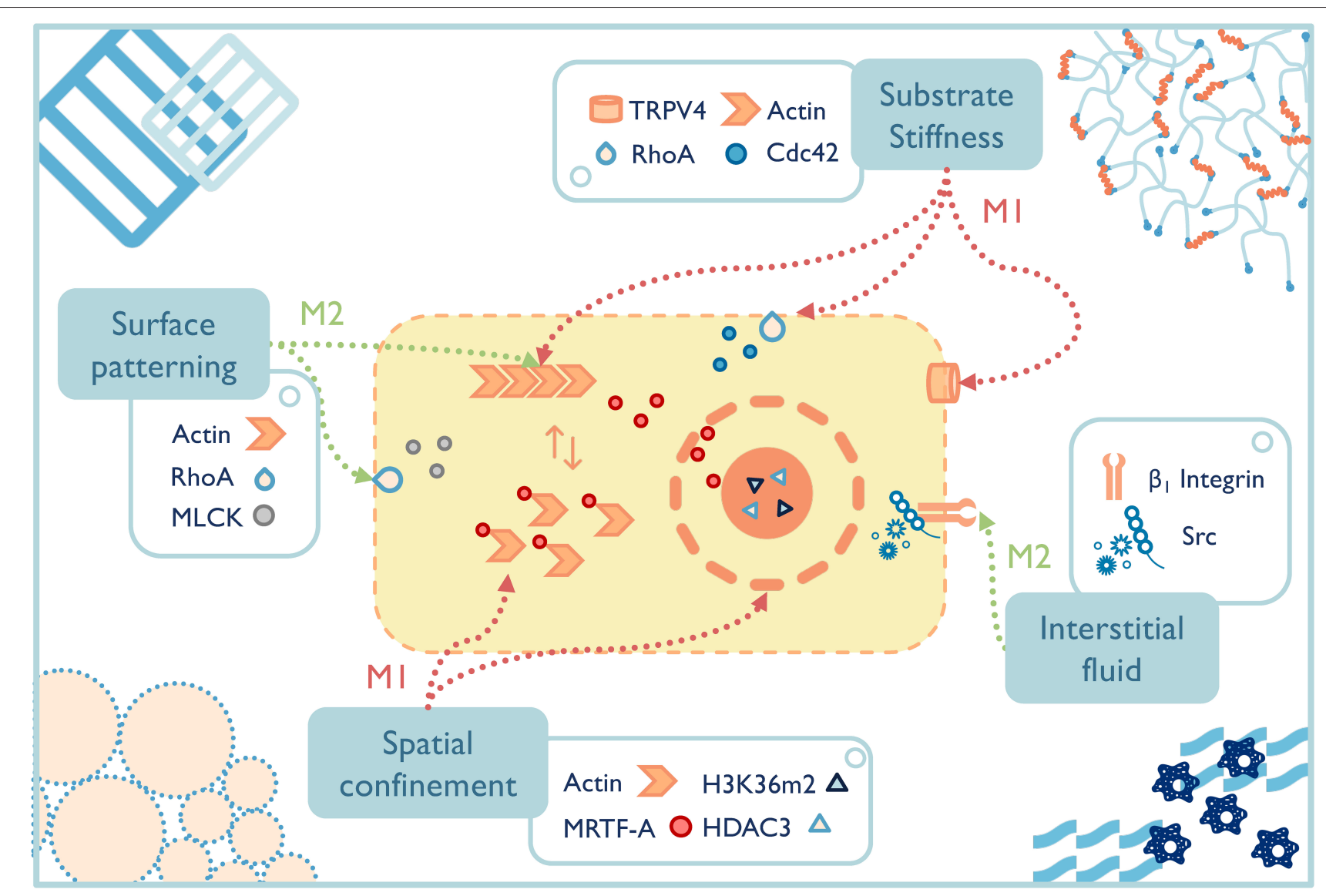

FIGURE 4 | The fate of macrophages can be greatly affected by material properties, both those inherent to the selected materials and the additional engineered functionality. Potential macrophage mechanotransduction pathways have been probed for a few properties, such as surface patterning (McWhorter et al., 2013), substrate stiffness (Patel et al., 2012; Scheraga et al., 2016; Gruber et al., 2018), spatial confinement (Jain and Vogel, 2018), and interstitial fluid (Li R. et al., 2018), while others remain to be elucidated. TRPV4, transient receptor potential cation channel subfamily $\vee$ member 4; RhoA, ras homolog family member A; Cdc 42, cell division cycle 42; MLCK, myosin light-chain kinase; HDAC, histone deacetylase 3; MRTF-A, myocardin-related transcription factor-A.

\section{MACROPHAGE-CENTERED IMMUNOMODULATORY BIOMATERIALS FOR FUNCTIONAL REPAIR}

The ultimate purpose of regenerative materials is to restore normal tissue function. This goal cannot be achieved solely by engaging one or two key cell types. To obtain functional recovery, the material must synergize with the systemic and local immune responses, as well as coordinate with the microenvironment and supporting cells. Because macrophages bridge innate immunity and adaptive immunity, a new paradigm was established to harness macrophage responses by immunomodulating biomaterials for endogenous repair (Sadtler et al., 2016; Wolf et al., 2019). A recent study demonstrated that synthetic porous scaffolds eliciting a Th2 adaptive immune response can achieve regenerative healing through a macrophage/IL-33 mechanism (Griffin et al., 2020). It's worth noting that although the specific peptide that this study used was a poor activator of macrophage innate immune signaling in vitro, when the peptide was presented in porous scaffolds in vivo, an IL-33-related type 2 myeloid cell recruitment and an antigen-specific immunity were induced to support tissue remodeling and skin regeneration. This further illustrated that material design should target the immune system as a whole, rather than one cell type, to deliver an optimal outcome.

Macrophages, as key facilitators of functional tissue repair, remain in the center of design for immunomodulatory biomaterials. In order to ensure that material designs achieve the designated goals of promoting the desired macrophage phenotype, material composition (e.g., natural vs. synthetic), scaffold physical properties (e.g., microstructure and viscous vs. elastic mechanical properties), and additional cues (e.g., chemokines, nanoparticles) must be carefully considered (Figure 5). The backbone material sets the cornerstone for the general immune response and the following design options. Naturally derived materials, like ECM components or decellularized tissues, have inherent cell-binding motifs (e.g., integrins, CD44) and can selectively promote a range of immune responses based on their composition (Badylak et al., 2008; Boddupalli et al., 2016; Sadtler et al., 2019). As an example, 


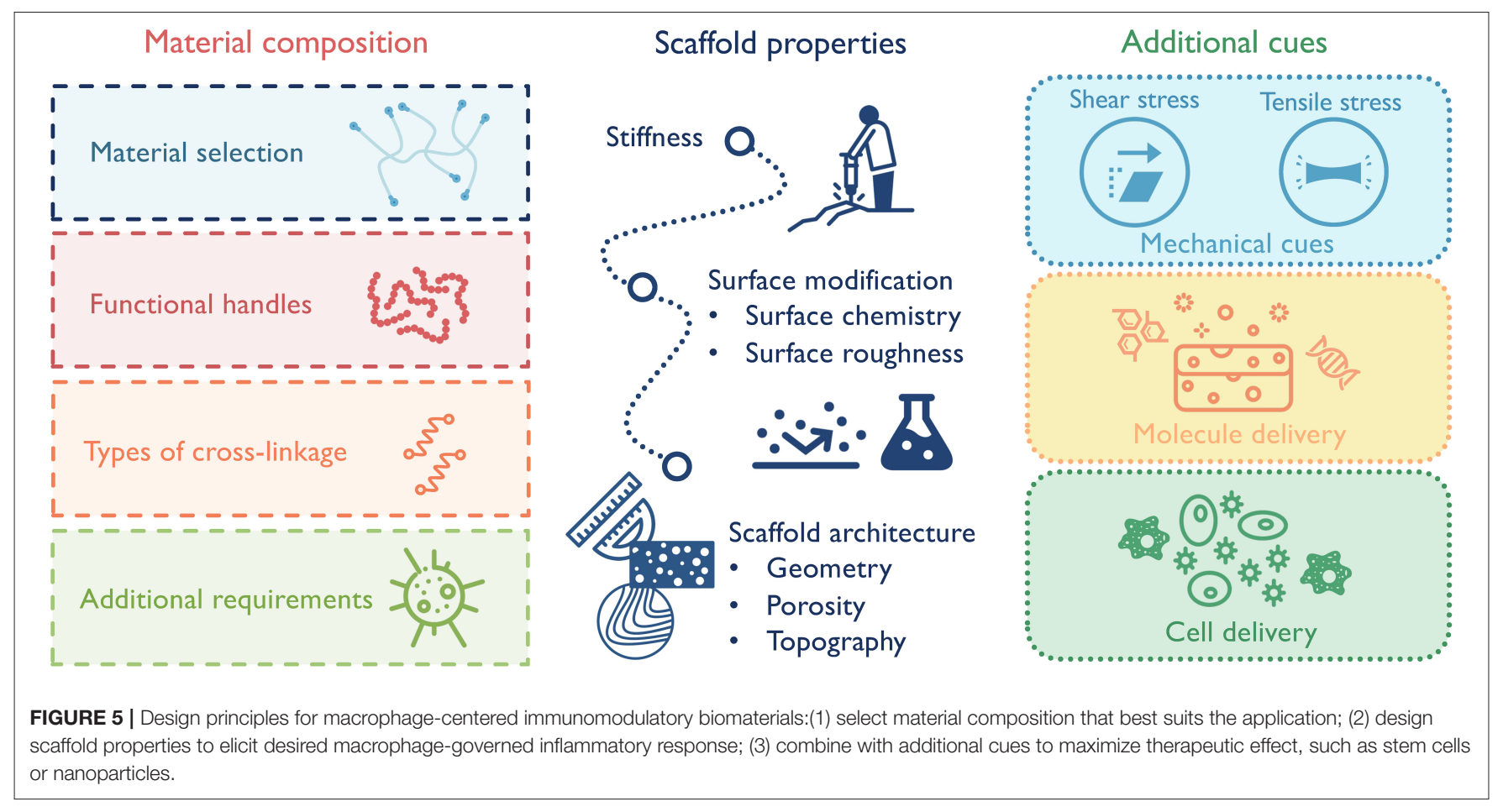

heparin and other sulfated polysaccharides have the ability to bind growth factors and some cytokines, many of which directly activate macrophages and, thus, dictate their phenotype (Capila and Linhardt, 2002). This ability has been exploited in one study to sequester heparin-binding factors in diabetic wounds to reduce inflammation and promote wound healing (Lohmann et al., 2017). Synthetic materials, such as polyethylene glycol (PEG), have high plasticity for chemical modification and are less immunogenetic. These substrates can serve as "clean slates" to release molecules or present factors spatially and/or temporally (Cha et al., 2017). Functional handles can also be incorporated into the scaffolds to further direct macrophage responses. For instance, different adhesion receptor engagement, like $\alpha \mathrm{V} \beta 3$ integrin, can be leveraged to alter macrophage phenotype (Kao et al., 2001; Antonov et al., 2011). In terms of scaffold properties, a few parameters impacting macrophage phenotype should be considered, including substrate stiffness, surface hydrophobicity, surface modification, and scaffold microstructure (McWhorter et al., 2015; Jain et al., 2019). While some features can be combined in one scaffold, it is often difficult to separately control mechanical and biochemical properties. For example, in chemically crosslinked hydrogels, the substrate stiffness is tied up with material degradation, ligand density and mesh size. Increasing stiffness by additional cross-linkages also leads to a slower degradation rate, a smaller mesh size/diffusion rate, and an increased local ligand density. Therefore, modulating macrophage response with scaffold stiffness in these systems cannot be easily decoupled with the other confounding factors. Also, when manipulating matrix properties, care should be taken to consider not only macrophage response, but also macrophages' coordination with other cell types to achieve synergistic responses. In the case of scaffold porosity, a smaller pore size may be in favor of M2 macrophage response, but larger pore size could be beneficial for the growth of blood vessels, which in the long run supports the implant success rate (Madden et al., 2010; Feng et al., 2011). Additionally, to avoid any unwanted pro-inflammatory macrophage activation, biomaterials should also be verified that they are substantially free of known toxic or harmful materials, such as endotoxins or residual cellular debris (Lieder et al., 2013).

In our lab, a new class of injectable biomaterials using hydrogel building blocks was designed to improve cellular infiltration and modulate host response (Griffin et al., 2015). A microporous annealed particle (MAP) scaffold is formed by interlinking the particles together, which contains an interconnected network of void space with channels that are on the length-scale of cells. Such a scaffold offers enormous tunability by virtue of its granular nature, where a bottomup approach to design starts at the individual particle. These building blocks have been fabricated using a variety of synthetic and natural backbone materials (e.g., PEG, hyaluronic acid) with a range of chemical modifications to allow for particle crosslinking, cargo delivery (e.g., growth factor, stem cells, DNA), and to influence cellular behavior (e.g., RGD). For example, particles are frequently engineered with RGD peptides to promote cellular infiltration and migration throughout the scaffold, while the inclusion of growth factors offers additional cues to traversing cells (Truong et al., 2019). The shape, size, and stiffness of the particles composing a MAP scaffold not only dictate bulk mechanical properties of the scaffold, but also set the internal landscape of the void space that is sensed by the cells. By ranging size, stiffness, and RGD concentration, one 
study was able to develop particles with an optimal combination that, when used as a MAP scaffold, demonstrated superior gene transfection capabilities (Truong et al., 2019). Yet the power of granular biomaterials extends beyond the design of individual particles. Including multiple particle species into a single scaffold can offer a higher level of material tunability. By incorporating particle heterogeneity, a scaffold may serve more than one primary function, such as promoting stem cell growth while simultaneously inhibiting bacterial growth (Cai et al., 2018). MAP scaffolds can also be designed with spatial heterogeneity, where physical or chemical gradients can be maintained during injection due to the jamming properties of granular materials (Darling et al., 2018; Riley et al., 2019). Remarkably, MAP gels have already demonstrated great promises in promoting functional tissue repair in wound healing and stroke with a reduced inflammatory response (e.g., reduced CD11b + immune cell infiltration) (Griffin et al., 2015, 2020; Sideris et al., 2016; Nih et al., 2017; Darling et al., 2020). Specifically, in stroke infarct areas filled with MAP gels, there is a much higher ratio of infiltrating pro-reparative arginase $1+($ Arg-1+) macrophage comparing to no treatment control (Sideris et al., 2019). Taken together, these results supported that MAP scaffold is not only appealing as a tool for elucidating the mechanotransduction pathways of macrophages, but also as a potent immunomodulatory platform for macrophagetargeting therapies.

\section{A LOOK INTO THE FUTURE}

Modern biomaterials continue to emerge and evolve, unlocking infinite potentials for tailoring macrophage-centered therapies. These materials are promising because they can offer a controlled and tunable microenvironment, incorporating mechanical, and biochemical properties, as well as their temporal and spatial presentation. Although research on new biomaterials and material designs for immunomodulation are burgeoning in recent years, a refocus on directing macrophage behavior to achieve suitable immune responses needs to be emphasized. An optimal biomaterial design should act synergistically with additional mechanical cues, molecules, or cells (that are delivered or found endogenously) to coax macrophages into pro-regenerative phenotypes. These macrophages, together with tissue-resident cells and recruited immune cells, can collectively orchestrate the regenerative process.

\section{REFERENCES}

Adams, S., Wuescher, L. M., Worth, R., and Yildirim-Ayan, E. (2019). Mechano-immunomodulation: mechanoresponsive changes in macrophage activity and polarization. Ann. Biomed. Eng. 47, 2213-2231. doi: 10.1007/s10439-019-02302-4

Ajami, B., Bennett, J. L., Krieger, C., Tetzlaff, W., and Rossi, F. M. (2007). Local self-renewal can sustain CNS microglia maintenance and function throughout adult life. Nat. Neurosci. 10, 1538-1543. doi: 10.1038/nn2014

Anderson, J. M., and Miller, K. M. (1984). Biomaterial biocompatibility and the macrophage. Biomaterials 5, 5-10. doi: 10.1016/0142-9612(84)90060-7
There is still much to be learned about macrophages and their roles in endogenous repair, such as the different contribution of tissue-resident macrophages and their bone marrow-derived counterparts during healing and host responses. A common nomenclature of dynamic macrophage phenotype, taking into account both macrophages' heterogeneity and plasticity, should also be unified to benefit both in vitro and in vivo studies. Currently, the investigation of macrophage mechanotransduction pathways remains an important area of research, as it can direct new material design strategies to harness macrophage activity for endogenous tissue regeneration and disease treatment. Armed with the booming knowledge of macrophage and macrophage-material response, the next generation of macrophage-centered immunomodulatory biomaterials should be able to conquer broader land and achieve more and more successful translation into clinical settings.

\section{AUTHOR CONTRIBUTIONS}

YL is credited with the conception and writing of the manuscript as well as the creation of figures. TS provided valuable edits, suggestions, and feedback. All authors contributed to the article and approved the submitted version.

\section{FUNDING}

We acknowledge funding from the National Institutes of Health (R01AI152568).

\section{ACKNOWLEDGMENTS}

We would like to acknowledge Michelle Campbell, $\mathrm{PhD}$ from Duke Engineering Graduate Communications and Intercultural Programs Team for her kind instruction and critical suggestion on the manuscript. We would like to thank Lindsay Riley for her helpful input, Jun Chen, $\mathrm{PhD}$ and Elle Caston for their proofreading on the manuscript. We also want to thank our lab for the support and help.

\section{SUPPLEMENTARY MATERIAL}

The Supplementary Material for this article can be found online at: https://www.frontiersin.org/articles/10.3389/fbioe. 2020.609297/full\#supplementary-material

Anderson, J. M., Rodriguez, A., and Chang, D. T. (2008). Foreign body reaction to biomaterials. Semin. Immunol. 20, 86-100. doi: 10.1016/j.smim.2007. 11.004

Andorko, J. I., and Jewell, C. M. (2017). Designing biomaterials with immunomodulatory properties for tissue engineering and regenerative medicine. Bioeng. Transl. Med. 2, 139-155. doi: 10.1002/btm2. 10063

Antonov, A. S., Antonova, G. N., Munn, D. H., Mivechi, N., Lucas, R., Catravas, J. D., et al. (2011). alphaVbeta3 integrin regulates macrophage inflammatory responses via PI3 kinase/Akt-dependent NF-kappaB activation. J. Cell. Physiol. 226, 469-476. doi: 10.1002/jcp.22356 
Aschoff, L. (1924). "Das reticulo-endotheliale system," in Ergebnisse der Inneren Medizin und Kinderheilkunde (Berlin: Springer), 1-118. doi: 10.1007/978-3-642-90639-8_1

Badylak, S. F., Valentin, J. E., Ravindra, A. K., McCabe, G. P., and StewartAkers, A. M. (2008). Macrophage phenotype as a determinant of biologic scaffold remodeling. Tissue Eng. A 14, 1835-1842. doi: 10.1089/ten.tea.200 7.0264

Bain, C. C., Bravo-Blas, A., Scott, C. L., Perdiguero, E. G., Geissmann, F., Henri, S., et al. (2014). Constant replenishment from circulating monocytes maintains the macrophage pool in the intestine of adult mice. Nat. Immunol. 15, 929-937. doi: $10.1038 /$ ni.2967

Bajpai, G., Schneider, C., Wong, N., Bredemeyer, A., Hulsmans, M., Nahrendorf, M., et al. (2018). The human heart contains distinct macrophage subsets with divergent origins and functions. Nat. Med. 24, 1234-1245. doi: 10.1038/s41591-018-0059-x

Bannon, P., Wood, S., Restivo, T., Campbell, L., Hardman, M. J., and Mace, K. A. (2013). Diabetes induces stable intrinsic changes to myeloid cells that contribute to chronic inflammation during wound healing in mice. Dis. Model. Mech. 6, 1434-1447. doi: $10.1242 / \mathrm{dmm} .012237$

Biswas, S. K., and Mantovani, A. (2010). Macrophage plasticity and interaction with lymphocyte subsets: cancer as a paradigm. Nat. Immunol. 11, 889-896. doi: $10.1038 /$ ni.1937

Blakney, A. K., Swartzlander, M. D., and Bryant, S. J. (2012). The effects of substrate stiffness on the in vitro activation of macrophages and in vivo host response to poly(ethylene glycol)-based hydrogels. J. Biomed. Mater. Res. A 100, 1375-1386. doi: 10.1002/jbm.a.34104

Boddupalli, A., Zhu, L., and Bratlie, K. M. (2016). Methods for implant acceptance and wound healing: material selection and implant location modulate macrophage and fibroblast phenotypes. Adv. Healthc. Mater. 5, 2575-2594. doi: 10.1002/adhm.201600532

Bota, P. C., Collie, A. M., Puolakkainen, P., Vernon, R. B., Sage, E. H., Ratner, B. D., et al. (2010). Biomaterial topography alters healing in vivo and monocyte/macrophage activation in vitro. J. Biomed. Mater. Res. A 95, 649-657. doi: 10.1002/jbm.a.32893

Brodbeck, W. G., Patel, J., Voskerician, G., Christenson, E., Shive, M. S., Nakayama, Y., et al. (2002). Biomaterial adherent macrophage apoptosis is increased by hydrophilic and anionic substrates in vivo. Proc. Natl. Acad. Sci. U.S.A. 99, 10287-10292. doi: $10.1073 /$ pnas. 162124199

Brown, B. N., Londono, R., Tottey, S., Zhang, L., Kukla, K. A., Wolf, M. T., et al. (2012). Macrophage phenotype as a predictor of constructive remodeling following the implantation of biologically derived surgical mesh materials. Acta Biomater. 8, 978-987. doi: 10.1016/j.actbio.2011.11.031

Brown, B. N., Sicari, B. M., and Badylak, S. F. (2014). Rethinking regenerative medicine: a macrophage-centered approach. Front. Immunol. 5:510. doi: $10.3389 /$ fimmu.2014.00510

Cai, B., Zou, Q., Zuo, Y., Mei, Q., Ma, J., Lin, L., et al. (2018). Injectable gel constructs with regenerative and anti-infective dual effects based on assembled chitosan microspheres. ACS Appl. Mater. Interfaces 10, 25099-25112. doi: $10.1021 /$ acsami.8b06648

Capila, I., and Linhardt, R. J. (2002). Heparin-protein interactions. Angew. Chem. Int. Ed. Engl. 41, 391-412. doi: 10.1002/1521-3773(20020201)41:3<390::AID-ANIE390>3.0.CO;2-B

Cha, B. H., Shin, S. R., Leijten, J., Li, Y. C., Singh, S., Liu, J. C., et al. (2017). Integrinmediated interactions control macrophage polarization in 3D hydrogels. Adv. Healthc. Mater. 6:1700289. doi: 10.1002/adhm.201700289

Chen, S., Jones, J. A., Xu, Y., Low, H. Y., Anderson, J. M., and Leong, K. W. (2010). Characterization of topographical effects on macrophage behavior in a foreign body response model. Biomaterials 31, 3479-3491. doi: 10.1016/j.biomaterials.2010.01.074

Chorro, L., Sarde, A., Li, M., Woollard, K. J., Chambon, P., Malissen, B., et al. (2009). Langerhans cell (LC) proliferation mediates neonatal development, homeostasis, and inflammation-associated expansion of the epidermal LC network. J. Exp. Med. 206, 3089-3100. doi: 10.1084/jem.20091586

Christman, K. L. (2019). Biomaterials for tissue repair. Science 363, 340-341. doi: $10.1126 /$ science.aar2955
Coleman, D. L., King, R. N., and Andrade, J. D. (1974). The foreign body reaction: a chronic inflammatory response. J. Biomed. Mater. Res. 8, 199-211. doi: $10.1002 / j b m .820080503$

Collier, T. O., Anderson, J. M., Brodbeck, W. G., Barber, T., and Healy, K. E. (2004). Inhibition of macrophage development and foreign body giant cell formation by hydrophilic interpenetrating polymer network. J. Biomed. Mater. Res. A 69, 644-650. doi: 10.1002/jbm.a.30030

Czernielewski, J. M., and Demarchez, M. (1987). Further evidence for the selfreproducing capacity of Langerhans cells in human skin. J. Invest. Dermatol. 88, 17-20. doi: 10.1111/1523-1747.ep12464659

Daley, J. M., Brancato, S. K., Thomay, A. A., Reichner, J. S., and Albina, J. E. (2010). The phenotype of murine wound macrophages. J. Leukoc. Biol. 87, 59-67. doi: 10.1189/jlb.0409236

Darling, N. J., Sideris, E., Hamada, N., Carmichael, S. T., and Segura, T. (2018). injectable and spatially patterned microporous annealed particle (map) hydrogels for tissue repair applications. Adv. Sci. 5:1801046. doi: 10.1002/advs.201801046

Darling, N. J., Xi, W., Sideris, E., Anderson, A. R., Pong, C., Carmichael, S. T., et al. (2020). Click by click microporous annealed particle (MAP) scaffolds. $A d v$. Healthc. Mater. 9:e1901391. doi: 10.1002/adhm.201901391

Edwards, J. P., Zhang, X., Frauwirth, K. A., and Mosser, D. M. (2006). Biochemical and functional characterization of three activated macrophage populations. J. Leukoc. Biol. 80, 1298-1307. doi: 10.1189/jlb.0406249

Eming, S. A., Koch, M., Krieger, A., Brachvogel, B., Kreft, S., Bruckner-Tuderman, L., et al. (2010). Differential proteomic analysis distinguishes tissue repair biomarker signatures in wound exudates obtained from normal healing and chronic wounds. J. Proteome Res. 9, 4758-4766. doi: 10.1021/pr100456d

Eming, S. A., Martin, P., and Tomic-Canic, M. (2014). Wound repair and regeneration: mechanisms, signaling, and translation. Sci. Transl. Med. 6:265sr266. doi: 10.1126/scitranslmed.3009337

Epelman, S., Lavine, K. J., Beaudin, A. E., Sojka, D. K., Carrero, J. A., Calderon, B., et al. (2014). Embryonic and adult-derived resident cardiac macrophages are maintained through distinct mechanisms at steady state and during inflammation. Immunity 40, 91-104. doi: 10.1016/j.immuni.2013. 11.019

Feng, B., Jinkang, Z., Zhen, W., Jianxi, L., Jiang, C., Jian, L., et al. (2011). The effect of pore size on tissue ingrowth and neovascularization in porous bioceramics of controlled architecture in vivo. Biomed. Mater. 6:015007. doi: 10.1088/1748-6041/6/1/015007

Garg, K., Pullen, N. A., Oskeritzian, C. A., Ryan, J. J., and Bowlin, G. L. (2013). Macrophage functional polarization (M1/M2) in response to varying fiber and pore dimensions of electrospun scaffolds. Biomaterials 34, 4439-4451. doi: 10.1016/j.biomaterials.2013.02.065

Ghosn, E. E., Cassado, A. A., Govoni, G. R., Fukuhara, T., Yang, Y., Monack, D. M., et al. (2010). Two physically, functionally, and developmentally distinct peritoneal macrophage subsets. Proc. Natl. Acad. Sci. U.S.A. 107, 2568-2573. doi: 10.1073/pnas.0915000107

Ginhoux, F., Greter, M., Leboeuf, M., Nandi, S., See, P., Gokhan, S., et al. (2010). Fate mapping analysis reveals that adult microglia derive from primitive macrophages. Science 330, 841-845. doi: 10.1126/science.1194637

Ginhoux, F., and Jung, S. (2014). Monocytes and macrophages: developmental pathways and tissue homeostasis. Nat. Rev. Immunol. 14, 392-404. doi: $10.1038 /$ nri3671

Ginhoux, F., Schultze, J. L., Murray, P. J., Ochando, J., and Biswas, S. K. (2016). New insights into the multidimensional concept of macrophage ontogeny, activation and function. Nat. Immunol. 17, 34-40. doi: 10.1038/ni.3324

Gordon, S. (1995). The macrophage. Bioessays 17, 977-986. doi: 10.1002/bies.950171111

Gordon, S. (2008). Elie metchnikoff: father of natural immunity. Eur. J. Immunol. 38, 3257-3264. doi: 10.1002/eji.200838855

Gordon, S., and Taylor, P. R. (2005). Monocyte and macrophage heterogeneity. Nat. Rev. Immunol. 5, 953-964. doi: 10.1038/nri1733

Gordy, C., Pua, H., Sempowski, G. D., and He, Y. W. (2011). Regulation of steady-state neutrophil homeostasis by macrophages. Blood 117, 618-629. doi: 10.1182/blood-2010-01-265959

Goreish, H. H., Lewis, A. L., Rose, S., and Lloyd, A. W. (2004). The effect of phosphorylcholine-coated materials on the inflammatory response and fibrous 
capsule formation: in vitro and in vivo observations. J. Biomed. Mater. Res. A 68, 1-9. doi: 10.1002/jbm.a.10141

Goren, I., Muller, E., Schiefelbein, D., Christen, U., Pfeilschifter, J., Muhl, H., et al. (2007). Systemic anti-TNFalpha treatment restores diabetes-impaired skin repair in ob/ob mice by inactivation of macrophages. J. Invest. Dermatol. 127, 2259-2267. doi: 10.1038/sj.jid.5700842

Gosselin, D., Link, V. M., Romanoski, C. E., Fonseca, G. J., Eichenfield, D. Z., Spann, N. J., et al. (2014). Environment drives selection and function of enhancers controlling tissue-specific macrophage identities. Cell 159, 1327-1340. doi: 10.1016/j.cell.2014.11.023

Gretzer, C., Emanuelsson, L., Liljensten, E., and Thomsen, P. (2006). The inflammatory cell influx and cytokines changes during transition from acute inflammation to fibrous repair around implanted materials. J. Biomater. Sci. Polym. Ed. 17, 669-687. doi: 10.1163/156856206777346340

Griffin, D. R., Weaver, W. M., Scumpia, P. O., Di Carlo, D., and Segura, T. (2015). Accelerated wound healing by injectable microporous gel scaffolds assembled from annealed building blocks. Nat. Mater. 14, 737-744. doi: 10.1038/nmat4294

Griffin, D. R., Archang, M. M., Kuan, C. H., Weaver, W. M., Weinstein, J. S., Feng, A. C., et al. (2020). Activating an adaptive immune response from a hydrogel scaffold imparts regenerative wound healing. Nat. Mater [Preprint]. doi: 10.1038/s41563-020-00844-w

Gruber, E., Heyward, C., Cameron, J., and Leifer, C. (2018). Toll-like receptor signaling in macrophages is regulated by extracellular substrate stiffness and Rho-associated coiled-coil kinase (ROCK1/2). Int. Immunol. 30, 267-278. doi: 10.1093/intimm/dxy027

Gruber, E. J., and Leifer, C. A. (2020). Molecular regulation of TLR signaling in health and disease: mechano-regulation of macrophages and TLR signaling. Innate. Immun. 26, 15-25. doi: 10.1177/1753425919838322

Hashimoto, D., Chow, A., Noizat, C., Teo, P., Beasley, M. B., Leboeuf, M., et al. (2013). Tissue-resident macrophages self-maintain locally throughout adult life with minimal contribution from circulating monocytes. Immunity 38, 792-804. doi: 10.1016/j.immuni.2013.04.004

Hernandez-Pando, R., Bornstein, Q. L., Aguilar Leon, D., Orozco, E. H., Madrigal, V. K., and Martinez Cordero, E. (2000). Inflammatory cytokine production by immunological and foreign body multinucleated giant cells. Immunology 100, 352-358. doi: 10.1046/j.1365-2567.2000.00025.x

Homsy, C. A. (1970). Bio-compatibility in selection of materials for implantation. J. Biomed. Mater. Res. 4, 341-356. doi: 10.1002/jbm.820040306

Jain, N., Moeller, J., and Vogel, V. (2019). Mechanobiology of macrophages: how physical factors coregulate macrophage plasticity and phagocytosis. Annu. Rev. Biomed. Eng. 21, 267-297. doi: 10.1146/annurev-bioeng-062117-121224

Jain, N., and Vogel, V. (2018). Spatial confinement downsizes the inflammatory response of macrophages. Nat. Mater. 17, 1134-1144. doi: 10.1038/s41563-018-0190-6

Jenney, C. R., and Anderson, J. M. (1999). Alkylsilane-modified surfaces: inhibition of human macrophage adhesion and foreign body giant cell formation. J. Biomed. Mater. Res. 46, 11-21. doi: 10.1002/(SICI)10974636(199907)46:1<11::AID-JBM2>3.0.CO;2-Y

Kao, W. J., Lee, D., Schense, J. C., and Hubbell, J. A. (2001). Fibronectin modulates macrophage adhesion and FBGC formation: the role of RGD, PHSRN, and PRRARV domains. J. Biomed. Mater. Res. 55, 79-88. doi: 10.1002/1097-4636(200104)55:1<79::AID-JBM110>3.0.CO;2-Z

Kao, W. J., McNally, A. K., Hiltner, A., and Anderson, J. M. (1995). Role for interleukin-4 in foreign-body giant cell formation on a poly(etherurethane urea) in vivo. J. Biomed. Mater. Res. 29, 1267-1275. doi: 10.1002/jbm.8202 91014

Krzyszczyk, P., Schloss, R., Palmer, A., and Berthiaume, F. (2018). The role of macrophages in acute and chronic wound healing and interventions to promote pro-wound healing phenotypes. Front. Physiol. 9:419. doi: 10.3389/fphys.2018.00419

Langevoort, H. (1970). The nomenclature of mononuclear phagocytic cells-proposal for a new classification. Mononuclear Phagocytes. Oxford: Blackwell Scientific Publications, 1-6.

Lavin, Y., Winter, D., Blecher-Gonen, R., David, E., Keren-Shaul, H., Merad, M., et al. (2014). Tissue-resident macrophage enhancer landscapes are shaped by the local microenvironment. Cell 159, 1312-1326. doi: $10.1016 /$ j.cell.2014.11.018
Leibovich, S. J., and Ross, R. (1975). The role of the macrophage in wound repair. a study with hydrocortisone and antimacrophage serum. Am. J. Pathol. 78, 71-100.

Li, J., Li, Y., Gao, B., Qin, C., He, Y., Xu, F., et al. (2018). Engineering mechanical microenvironment of macrophage and its biomedical applications. Nanomedicine 13, 555-576. doi: 10.2217/nnm-2017-0324

Li, R., Serrano, J. C., Xing, H., Lee, T. A., Azizgolshani, H., Zaman, M., et al. (2018). Interstitial flow promotes macrophage polarization toward an M2 phenotype. Mol. Biol. Cell 29, 1927-1940. doi: 10.1091/mbc.E18-03-0164

Lichanska, A. M., and Hume, D. A. (2000). Origins and functions of phagocytes in the embryo. Exp. Hematol. 28, 601-611. doi: 10.1016/S0301-472X(00) 00157-0

Lieder, R., Petersen, P. H., and Sigurjonsson, O. E. (2013). Endotoxins-the invisible companion in biomaterials research. Tissue Eng. B Rev. 19, 391-402. doi: 10.1089/ten.teb.2012.0636

Lohmann, N., Schirmer, L., Atallah, P., Wandel, E., Ferrer, R. A., Werner, C., et al. (2017). Glycosaminoglycan-based hydrogels capture inflammatory chemokines and rescue defective wound healing in mice. Sci. Transl. Med. 9:eaai9044. doi: 10.1126/scitranslmed.aai9044

Lucas, T., Waisman, A., Ranjan, R., Roes, J., Krieg, T., Muller, W., et al. (2010). Differential roles of macrophages in diverse phases of skin repair. J. Immunol. 184, 3964-3977. doi: 10.4049/jimmunol.0903356

Madden, L. R., Mortisen, D. J., Sussman, E. M., Dupras, S. K., Fugate, J. A., Cuy, J. L., et al. (2010). Proangiogenic scaffolds as functional templates for cardiac tissue engineering. Proc. Natl. Acad. Sci. U.S.A. 107, 15211-15216. doi: $10.1073 /$ pnas. 1006442107

Malyshev, I., and Malyshev, Y. (2015). Current concept and update of the macrophage plasticity concept: intracellular mechanisms of reprogramming and M3 macrophage "Switch" phenotype. Biomed Res. Int. 2015:341308. doi: 10.1155/2015/341308

Mantovani, A., Sica, A., Sozzani, S., Allavena, P., Vecchi, A., and Locati, M. (2004). The chemokine system in diverse forms of macrophage activation and polarization. Trends Immunol. 25, 677-686. doi: 10.1016/j.it.2004.09.015

Martin, P., and Leibovich, S. J. (2005). Inflammatory cells during wound repair: the good, the bad and the ugly. Trends Cell Biol. 15, 599-607. doi: $10.1016 /$ j.tcb.2005.09.002

Martinez, F. O., and Gordon, S. (2014). The M1 and M2 paradigm of macrophage activation: time for reassessment. F1000Prime Rep. 6:13. doi: 10.12703/P6-13

Martinez, F. O., Sica, A., Mantovani, A., and Locati, M. (2008). Macrophage activation and polarization. Front. Biosci. 13, 453-461. doi: 10.2741/2692

Matlaga, B. F., Yasenchak, L. P., and Salthouse, T. N. (1976). Tissue response to implanted polymers: the significance of sample shape. J. Biomed. Mater. Res. 10, 391-397. doi: 10.1002/jbm.820100308

McWhorter, F. Y., Davis, C. T., and Liu, W. F. (2015). Physical and mechanical regulation of macrophage phenotype and function. Cell. Mol. Life Sci. 72, 1303-1316. doi: 10.1007/s00018-014-1796-8

McWhorter, F. Y., Wang, T., Nguyen, P., Chung, T., and Liu, W. F. (2013). Modulation of macrophage phenotype by cell shape. Proc. Natl. Acad. Sci. U.S.A. 110, 17253-17258. doi: 10.1073/pnas.1308887110

Meli, V. S., Veerasubramanian, P. K., Atcha, H., Reitz, Z., Downing, T. L., and Liu, W. F. (2019). Biophysical regulation of macrophages in health and disease. J. Leukoc. Biol. 106, 283-299. doi: 10.1002/JLB.MR0318-126R

Mennens, S. F. B., van den Dries, K., and Cambi, A. (2017). "Role for mechanotransduction in macrophage and dendritic cell immunobiology," in Macrophages: Origin, Functions and Biointervention, ed. M. Kloc, (Cham: Springer), 209-242. doi: 10.1007/978-3-319-54090-0_9

Metchnikoff, E. (1883). Untersuchungen über die mesodermalen Phagocyten einiger Wirbeltiere. Biologisches centralblatt 3, 560-565.

Metchnikoff, E. (1907). Immunity in Infective Diseases. Cambridge: University Press. doi: 10.5962/bhl.title.31465

Mills, C. D. (2012). M1 and M2 macrophages: oracles of health and disease. Crit. Rev. Immunol. 32, 463-488. doi: 10.1615/CritRevImmunol.v32.i6.10

Mills, C. D. (2015). Anatomy of a discovery: $\mathrm{m} 1$ and $\mathrm{m} 2$ macrophages. Front. Immunol. 6:212. doi: 10.3389/fimmu.2015.00212

Mills, C. D., Kincaid, K., Alt, J. M., Heilman, M. J., and Hill, A. M. (2000). M1/M-2 macrophages and the Th1/Th2 paradigm. J. Immunol. 164, 6166-6173. doi: 10.4049/jimmunol.164.12.6166 
Minutti, C. M., Knipper, J. A., Allen, J. E., and Zaiss, D. M. (2016). "Tissuespecific contribution of macrophages to wound healing," in Seminars in Cell \& Developmental Biology, Vol. 61 (Academic Press), 3-11. doi: 10.1016/j.semcdb.2016.08.006

Mirza, R., DiPietro, L. A., and Koh, T. J. (2009). Selective and specific macrophage ablation is detrimental to wound healing in mice. Am. J. Pathol. 175, 2454-2462. doi: 10.2353/ajpath.2009.090248

Mirza, R., and Koh, T. J. (2011). Dysregulation of monocyte/macrophage phenotype in wounds of diabetic mice. Cytokine 56, 256-264. doi: 10.1016/j.cyto.2011.06.016

Mokarram, N., Merchant, A., Mukhatyar, V., Patel, G., and Bellamkonda, R. V. (2012). Effect of modulating macrophage phenotype on peripheral nerve repair. Biomaterials 33, 8793-8801. doi: 10.1016/j.biomaterials.2012.08.050

Mosser, D. M., and Edwards, J. P. (2008). Exploring the full spectrum of macrophage activation. Nat. Rev. Immunol. 8, 958-969. doi: 10.1038/nri2448

Murray, P. J., Allen, J. E., Biswas, S. K., Fisher, E. A., Gilroy, D. W., Goerdt, S., et al. (2014). Macrophage activation and polarization: nomenclature and experimental guidelines. Immunity 41, 14-20. doi: 10.1016/j.immuni.2014.06.008

Nathan, C. F., Murray, H. W., Wiebe, M. E., and Rubin, B. Y. (1983). Identification of interferon-gamma as the lymphokine that activates human macrophage oxidative metabolism and antimicrobial activity. J. Exp. Med. 158, 670-689. doi: $10.1084 /$ jem.158.3.670

Nih, L. R., Sideris, E., Carmichael, S. T., and Segura, T. (2017). Injection of Microporous Annealing Particle (MAP) Hydrogels in the Stroke Cavity Reduces Gliosis and Inflammation and Promotes NPC Migration to the Lesion. Adv. Mater. Weinheim 29:1606471. doi: 10.1002/adma.201606471

Novak, M. L., and Koh, T. J. (2013). Macrophage phenotypes during tissue repair. J. Leukoc. Biol. 93, 875-881. doi: 10.1189/jlb.1012512

Patel, N. R., Bole, M., Chen, C., Hardin, C. C., Kho, A. T., Mih, J., et al. (2012). Cell elasticity determines macrophage function. PLoS ONE 7:e41024. doi: 10.1371/journal.pone.0041024

Quinn, C. A., Connor, R. E., and Heller, A. (1997). Biocompatible, glucosepermeable hydrogel for in situ coating of implantable biosensors. Biomaterials 18, 1665-1670. doi: 10.1016/S0142-9612(97)00125-7

Ramirez, R. N., El-Ali, N. C., Mager, M. A., Wyman, D., Conesa, A., and Mortazavi, A. (2017). Dynamic gene regulatory networks of human myeloid differentiation. Cell Syst. 4, 416-429.e413. doi: 10.1016/j.cels.2017.03.005

Rice, J. J., Martino, M. M., De Laporte, L., Tortelli, F., Briquez, P. S., and Hubbell, J. A. (2013). Engineering the regenerative microenvironment with biomaterials. Adv. Healthc. Mater 2, 57-71. doi: 10.1002/adhm.2012 00197

Riley, L., Schirmer, L., and Segura, T. (2019). Granular hydrogels: emergent properties of jammed hydrogel microparticles and their applications in tissue repair and regeneration. Curr. Opin. Biotechnol. 60, 1-8. doi: 10.1016/j.copbio.2018.11.001

Rodriguez, A., Meyerson, H., and Anderson, J. M. (2009). Quantitative in vivo cytokine analysis at synthetic biomaterial implant sites. J. Biomed. Mater. Res. A 89, 152-159. doi: 10.1002/jbm.a.31939

Sadtler, K., Estrellas, K., Allen, B. W., Wolf, M. T., Fan, H., Tam, A. J., et al. (2016). Developing a pro-regenerative biomaterial scaffold microenvironment requires T helper 2 cells. Science 352, 366-370. doi: 10.1126/science.aad9272

Sadtler, K., Wolf, M. T., Ganguly, S., Moad, C. A., Chung, L., Majumdar, S., et al. (2019). Divergent immune responses to synthetic and biological scaffolds. Biomaterials 192, 405-415. doi: 10.1016/j.biomaterials.2018.11.002

Salmon-Ehr, V., Ramont, L., Godeau, G., Birembaut, P., Guenounou, M., Bernard, P., et al. (2000). Implication of interleukin-4 in wound healing. Lab. Invest 80 , 1337-1343. doi: 10.1038/labinvest.3780141

Sawyer, R. T., Strausbauch, P. H., and Volkman, A. (1982). Resident macrophage proliferation in mice depleted of blood monocytes by strontium-89. Lab. Invest $46,165-170$

Scheraga, R. G., Abraham, S., Niese, K. A., Southern, B. D., Grove, L. M., Hite, R. D., et al. (2016). TRPV4 Mechanosensitive Ion Channel Regulates Lipopolysaccharide-Stimulated Macrophage Phagocytosis. J. Immunol. 196, 428-436. doi: 10.4049/jimmunol.1501688

Schultz, G. S., and Wysocki, A. (2009). Interactions between extracellular matrix and growth factors in wound healing. Wound Repair. Regen. 17, 153-162. doi: 10.1111/j.1524-475X.2009.00466.x
Schulz, C., Gomez Perdiguero, E., Chorro, L., Szabo-Rogers, H., Cagnard, N., Kierdorf, K., et al. (2012). A lineage of myeloid cells independent of Myb and hematopoietic stem cells. Science 336, 86-90. doi: 10.1126/science.1219179

Shayan, M., Padmanabhan, J., Morris, A. H., Cheung, B., Smith, R., Schroers, J., et al. (2018). Nanopatterned bulk metallic glass-based biomaterials modulate macrophage polarization. Acta Biomater. 75, 427-438. doi: 10.1016/j.actbio.2018.05.051

Sideris, E., Griffin, D. R., Ding, Y. C., Li, S. R., Weaver, W. M., Di Carlo, D., et al. (2016). Particle hydrogels based on hyaluronic acid building blocks. Acs Biomater. Sci. Eng. 2, 2034-2041. doi: 10.1021/acsbiomaterials.6b00444

Sideris, E., Yu, A., Chen, J., Carmichael, S. T., and Segura, T. (2019). Hyaluronic acid particle hydrogels decrease cerebral atrophy and promote pro-reparative astrocyte/axonal infiltration in the core after ischemic stroke. bioRxiv 768291. doi: 10.1101/768291

Spiller, K. L., Anfang, R. R., Spiller, K. J., Ng, J., Nakazawa, K. R., Daulton, J. W., et al. (2014). The role of macrophage phenotype in vascularization of tissue engineering scaffolds. Biomaterials 35, 4477-4488. doi: 10.1016/j.biomaterials.2014.02.012

Spiller, K. L., and Koh, T. J. (2017). Macrophage-based therapeutic strategies in regenerative medicine. Adv. Drug Deliv. Rev 122, 74-83. doi: 10.1016/j.addr.2017.05.010

Spiller, K. L., Nassiri, S., Witherel, C. E., Anfang, R. R., Ng, J., Nakazawa, K. R., et al. (2015). Sequential delivery of immunomodulatory cytokines to facilitate the M1-to-M2 transition of macrophages and enhance vascularization of bone scaffolds. Biomaterials 37, 194-207. doi: 10.1016/j.biomaterials.2014.10.017

Springer, N. L., and Fischbach, C. (2016). Biomaterials approaches to modeling macrophage-extracellular matrix interactions in the tumor microenvironment. Curr. Opin. Biotechnol. 40, 16-23. doi: 10.1016/j.copbio.2016.02.003

Stein, M., Keshav, S., Harris, N., and Gordon, S. (1992). Interleukin 4 potently enhances murine macrophage mannose receptor activity: a marker of alternative immunologic macrophage activation. J. Exp. Med. 176, 287-292. doi: $10.1084 /$ jem.176.1.287

Stout, R. D., and Suttles, J. (2004). Functional plasticity of macrophages: reversible adaptation to changing microenvironments. J. Leukoc. Biol. 76, 509-513. doi: $10.1189 /$ jlb.0504272

Sussman, E. M., Halpin, M. C., Muster, J., Moon, R. T., and Ratner, B. D. (2014). Porous implants modulate healing and induce shifts in local macrophage polarization in the foreign body reaction. Ann. Biomed. Eng. 42, 1508-1516. doi: 10.1007/s10439-013-0933-0

Swartzlander, M. D., Barnes, C. A., Blakney, A. K., Kaar, J. L., Kyriakides, T. R., and Bryant, S. J. (2015). Linking the foreign body response and protein adsorption to PEG-based hydrogels using proteomics. Biomaterials 41, 26-36. doi: 10.1016/j.biomaterials.2014.11.026

Tamoutounour, S., Guilliams, M., Montanana Sanchis, F., Liu, H., Terhorst, D., Malosse, C., et al. (2013). Origins and functional specialization of macrophages and of conventional and monocyte-derived dendritic cells in mouse skin. Immunity 39, 925-938. doi: 10.1016/j.immuni.2013.10.004

Tauber, A. I. (2003). Metchnikoff and the phagocytosis theory. Nat. Rev. Mol. Cell. Biol. 4, 897-901. doi: 10.1038/nrm1244

Truong, N. F., Kurt, E., Tahmizyan, N., Lesher-Perez, S. C., Chen, M., Darling, N. J., et al. (2019). Microporous annealed particle hydrogel stiffness, void space size, and adhesion properties impact cell proliferation, cell spreading, and gene transfer. Acta Biomater. 94, 160-172. doi: 10.1016/j.actbio.2019. 02.054

Underhill, D. M., Gordon, S., Imhof, B. A., Nunez, G., and Bousso, P. (2016). Elie metchnikoff (1845-1916): celebrating 100 years of cellular immunology and beyond. Nat. Rev. Immunol. 16, 651-656. doi: 10.1038/nri.2016.89

Van Furth, R. (1980). "Cells of the mononuclear phagocyte system," in Mononuclear phagocytes. (Dordrecht: Springer), 1-40. doi: 10.1007/978-94-009-8793-7_1

van Furth, R., Cohn, Z., Hirsch, J., Humphrey, J., Spector, W., and Langevoort, H. (1972a). The mononuclear phagocyte system: a new classification of macrophages, monocytes, and their precursor cells. Bull. World Health Organ. 46:845

van Furth, R., Cohn, Z. A., Hirsch, J. G., Humphrey, J. H., Spector, W. G., and Langevoort, H. L. (1972b). The mononuclear phagocyte system: a new classification of macrophages, monocytes, and their precursor cells. Bull. World Health Organ 46, 845-852. 
Van Goethem, E., Guiet, R., Balor, S., Charriere, G. M., Poincloux, R., Labrousse, A., et al. (2011). Macrophage podosomes go 3D. Eur. J. Cell Biol. 90, 224-236. doi: 10.1016/j.ejcb.2010.07.011

Veiseh, O., Doloff, J. C., Ma, M., Vegas, A. J., Tam, H. H., Bader, A. R., et al. (2015). Size- and shape-dependent foreign body immune response to materials implanted in rodents and non-human primates. Nat. Mater. 14, 643-651. doi: $10.1038 /$ nmat 4290

Voskerician, G., Shive, M. S., Shawgo, R. S., von Recum, H., Anderson, J. M., Cima, M. J., et al. (2003). Biocompatibility and biofouling of MEMS drug delivery devices. Biomaterials 24, 1959-1967. doi: 10.1016/S0142-9612(02)00565-3

Wang, T., Luu, T. U., Chen, A., Khine, M., and Liu, W. F. (2016). Topographical modulation of macrophage phenotype by shrink-film multi-scale wrinkles. Biomater. Sci 4, 948-952. doi: 10.1039/C6BM00224B

Wang, Z., Cui, Y., Wang, J., Yang, X., Wu, Y., Wang, K., et al. (2014). The effect of thick fibers and large pores of electrospun poly(epsilon-caprolactone) vascular grafts on macrophage polarization and arterial regeneration. Biomaterials 35, 5700-5710. doi: 10.1016/j.biomaterials.2014.03.078

Wells, J. M., and Watt, F. M. (2018). Diverse mechanisms for endogenous regeneration and repair in mammalian organs. Nature 557, 322-328. doi: 10.1038/s41586-018-0073-7

Wen, Y., Gu, J., Li, S. L., Reddy, M. A., Natarajan, R., and Nadler, J. L. (2006). Elevated glucose and diabetes promote interleukin-12 cytokine gene expression in mouse macrophages. Endocrinology 147, 2518-2525. doi: 10.1210/en.2005-0519

Willenborg, S., and Eming, S. A. (2014). Macrophages sensors and effectors coordinating skin damage and repair. J. Dtsch Dermatol. Ges. 12, 214-221, 214-223. doi: $10.1111 /$ ddg. 12290

Wills, Q. F., Mellado-Gomez, E., Nolan, R., Warner, D., Sharma, E., Broxholme, J., et al. (2017). The nature and nurture of cell heterogeneity: accounting for macrophage gene-environment interactions with single-cell RNA-Seq. BMC Genomics 18:53. doi: 10.1186/s12864-016-3445-0

Witherel, C. E., Sao, K., Brisson, B. K., Han, B., Volk, S. W., Petrie, R. J., et al. (2020). Regulation of extracellular matrix assembly and structure by hybrid M1/M2 macrophages. bioRxiv [Preprint]. doi: 10.1101/2020.08.21.261933
Wolf, M. T., Ganguly, S., Wang, T. L., Anderson, C. W., Sadtler, K., Narain, R., et al. (2019). A biologic scaffold-associated type 2 immune microenvironment inhibits tumor formation and synergizes with checkpoint immunotherapy. Sci. Transl. Med. 11:eaat7973. doi: 10.1126/scitranslmed.aat7973

Wynn, T. A., Chawla, A., and Pollard, J. W. (2013). Macrophage biology in development, homeostasis and disease. Nature 496, 445-455. doi: $10.1038 /$ nature 12034

Wysocki, A. B., Staiano-Coico, L., and Grinnell, F. (1993). Wound fluid from chronic leg ulcers contains elevated levels of metalloproteinases MMP-2 and MMP-9. J. Invest. Dermatol. 101, 64-68. doi: 10.1111/1523-1747.ep12359590

Xue, J., Schmidt, S. V., Sander, J., Draffehn, A., Krebs, W., Quester, I., et al. (2014). Transcriptome-based network analysis reveals a spectrum model of human macrophage activation. Immunity 40, 274-288. doi: 10.1016/j.immuni.2014.01.006

Yona, S., Kim, K. W., Wolf, Y., Mildner, A., Varol, D., Breker, M., et al. (2013). Fate mapping reveals origins and dynamics of monocytes and tissue macrophages under homeostasis. Immunity 38, 79-91. doi: 10.1016/j.immuni.2012. 12.001

Yu, T., Wang, W., Nassiri, S., Kwan, T., Dang, C., Liu, W., et al. (2016a). Temporal and spatial distribution of macrophage phenotype markers in the foreign body response to glutaraldehyde-crosslinked gelatin hydrogels. J. Biomater. Sci. Polym. Ed. 27, 721-742

Yu, Y., Wu, R. X., Yin, Y., and Chen, F. M. (2016b). Directing immunomodulation using biomaterials for endogenous regeneration. J Mater Chem B 4, 569-584 doi: 10.1039/C5TB02199E

Conflict of Interest: The authors declare that the research was conducted in the absence of any commercial or financial relationships that could be construed as a potential conflict of interest.

Copyright (C) 2020 Liu and Segura. This is an open-access article distributed under the terms of the Creative Commons Attribution License (CC BY). The use, distribution or reproduction in other forums is permitted, provided the original author(s) and the copyright owner(s) are credited and that the original publication in this journal is cited, in accordance with accepted academic practice. No use, distribution or reproduction is permitted which does not comply with these terms. 